\title{
Shear Strength Deterioration of Compacted Residual Soils under a Wind Turbine due to Drying-Wetting Cycles and Vibrations
}

\author{
Yan-Ming Zhou, ${ }^{1,2}$ Zong-Wei Deng $\mathbb{D}^{2,3}{ }^{2,3}$ Zi-Jian Fan, ${ }^{1}$ and Wen-Jie Liu ${ }^{4}$ \\ ${ }^{1}$ School of Civil Engineering, Changsha University of Science \& Technology, Changsha 410114, China \\ ${ }^{2}$ Hunan City University Design and Research Institute Co., Ltd., Changsha 410008, China \\ ${ }^{3}$ College of Civil Engineering, Hunan City University, Yiyang 413049, China \\ ${ }^{4}$ Hunan Communications Research Institute Co., Ltd., Changsha 410007, China \\ Correspondence should be addressed to Zong-Wei Deng; dengzongwei@hncu.edu.cn
}

Received 19 October 2021; Accepted 11 November 2021; Published 13 December 2021

Academic Editor: Mingfeng Lei

Copyright $\odot 2021$ Yan-Ming Zhou et al. This is an open access article distributed under the Creative Commons Attribution License, which permits unrestricted use, distribution, and reproduction in any medium, provided the original work is properly cited.

\begin{abstract}
The soil beneath a wind turbine withstands not only environmental impacts but also continuous vibrations transmitted from the superstructure. This paper presents an experimental study of the deterioration characteristics of shear strengths of residual soils affected by drying-wetting cycles and continuous vibrations. A series of triaxial tests were performed on compacted residual soil specimens after various drying-wetting cycles and vibrations. The influences of drying-wetting cycles and vibrations on the shear strengths of residual soils with different compaction degrees were analyzed. The results demonstrate that the shear strength and cohesion of compacted residual soils decreased as the number of drying-wetting cycles increased, and they tended to be stable after three drying-wetting cycles. The angle of internal friction decreased linearly with the reduction of compaction degree but was generally not affected by drying-wetting cycles. The shear strength of compacted residual soils also decreased because of continuous vibrations. After 10000 vibrations, the strength was stabilized gradually. Both the cohesion and angle of internal friction showed dynamic attenuation phenomenon. Finally, a modified Mohr-Coulomb strength equation considering the effects of drying-wetting cycles and vibrations was established. This equation could be used to predict the shear strength of compacted residual soils and further estimate the embedded depth of wind turbine foundations.
\end{abstract}

\section{Introduction}

Wind power generation technology has been developed rapidly in recent decades, making wind power the third largest power source after coal-fired power and hydropower. Although wind resources are more abundant in offshore areas, onshore wind farms have been a great concern because of their relatively low investment and mature technology [1]. For example, China has built 42,000 MW wind turbines in several provinces in the south, where hilly, plateau, and mountainous terrains exist, from 2016 to 2020 [2, 3]. Wind turbines in these regions are installed at the top of hills in order to gain sufficient wind energy (Figure 1). Thus, the foundations are often supported by strongly weathered rocks and residual soils. The mechanical properties of these materials are relatively weak and can be reduced under cyclic drying-wetting conditions $[4,5]$. On the other hand, the major force on a wind turbine is the dynamic wind load, which could produce considerable vibrations on the structure. The continuous vibrations will further induce increased stresses, strains, and deformations in the foundation and subsoil [6]. Obviously, the combined effect of cyclic drying-wetting environment and continuous vibrations will greatly reduce the strength of the subsoil and cause instability of the wind turbine foundation.

Many studies have been carried out to investigate the performance of wind turbine foundations and the subsoil via theoretical analyses, numerical calculations, and field monitoring. Vahdatirad et al. [7] and Liu et al. [8] applied probabilistic reliability theory to the analysis of bearing 


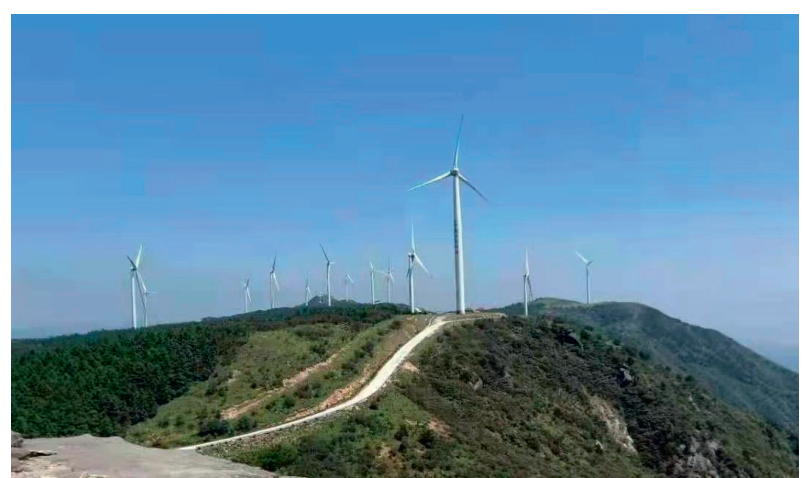

FIgURE 1: Wind driven generator at hilltop.

capacity and the stability of wind turbine foundations considering spatial variability of parameters. Pasten et al. [9] analyzed the responses of a foundation and its subsoil under cyclic loading using the mixed numerical method. It was found that the vertical settlement, horizontal displacement, footing rotation, and stress redistribution within the soil mass change with increasing number of load cycles. In addition, the displacement and rotation become more pronounced as the cyclic load amplitude increases. Madaschi et al. [10] conducted model tests on the dynamic behavior of shallow square foundation of a wind turbine under the rocking motion of the tower. The authors reported that the vibration of the wind turbine tower induces a sort of forced, damped harmonic excitation in the shallow foundation. Gao et al. [6] and Deng et al. [1] conducted numerical simulations and physical model tests on a $2 \mathrm{MW}$ wind turbine subjected to random wind loads. Currently, there are also many unsaturated constitutive models that can reasonably predict the mechanical behavior of unsaturated soils under monotonic loading, such as those proposed by Russell and Khalili [11] and $\mathrm{Li}$ and Yang [12]. The results demonstrated that the dynamic amplification factor strongly depends on the wind speed and spatial position and that the responses of the shallow foundation of a wind turbine are significantly affected by dynamic wind loads.

The mechanical properties of soil subjected to a cyclic drying-wetting process or loading alone have also received much attention. Xu et al. [13], Rayhania et al. [14, 15], and Zhang et al. [16] reported that the desiccation cracking induced by a cyclic drying-wetting process is the main reason for the strength degradation of soils. $\mathrm{Ng}$ et al. [17] studied the effects of dry/wet ratio and stress ratio on unsaturated fully weathered tuff and found that the dry-wet cycle led to a nonlinear increase in the small strain shear modulus. Monghassem et al. [18] analyzed the influence of dry and wet cycles on clay in Izad Khast Castle, pointing out that the increase of suction will raise the effective friction angle and dilatancy of clay linearly. Pasculli et al. [19] indicated the change of water content in the dry-wet cycle would lead to the change of porosity by laboratory tests. In order to understand the influence of drying-wetting cycles on the saturated shear strength characteristics of undisturbed residual soil, Sayem [20] conducted consolidation drainage triaxial test and discovered that the cohesion and internal friction angle decreased with the increase in dryingwetting cycles, while proposing a function describing the attenuation rate of saturated shear strength of samples.

However, few studies are focused on the evolution of mechanical behavior of soil underlying the shallow foundation of wind turbines. The purpose of this study is thus to investigate the shear strength deterioration of compacted residual soils under a wind turbine affected by dryingwetting cycles and vibrations. Residual soil specimens are prepared at various compaction degrees. Then, different numbers of drying-wetting cycles and vibrations are imposed on the specimens. Afterward, triaxial shearing was performed under different confining pressures to determine the stress-strain relationships and shear strength parameters of residual soils. The effects of drying-wetting cycles and continuous vibrations on the shear strength were analyzed. On this basis, a modified Mohr-Coulomb strength equation considering those effects was developed and then employed to estimate the bearing capacity of the soil. The findings could provide guidance for the design of wind turbine foundations on residual soils.

\section{Materials and Methods}

2.1. Material Properties. The studied soil was collected from the Qiaoshi Wind Farm located in Guiyang County, Hunan Province, China. Many $2 \mathrm{MW}$ horizontal-axis wind turbines were installed in this wind farm, and the total mass of each wind turbine was approximately $294.0 \mathrm{t}$. This region has a subtropical monsoon climate, with abundant rainfall and distinctive seasons. The landscape is characterized by low hills with an elevation of $400-580 \mathrm{~m}$. The land is covered by a layer of 5.1-8.2 m thick residual soils. The bedrock is medium- and fine-grained sandstone with various weathering degrees.

Table 1 shows the physical properties of strata of the wind farm. The residual soil was sampled at the bearing stratum of a wind turbine foundation. The grain size distribution of the soil is presented in Figure 2, and relative parameters are shown in Table 2. The material can be classified as silty sand according to the Chinese specification GB/T 50123-2019 [21]. However, particles in the material with size $<0.075 \mathrm{~mm}$ still accounts for about 35\%, which results in obvious cohesive soil feature.

2.2. Specimen Preparation. The residual soil was used to prepare specimens with $50 \mathrm{~mm}$ in diameter and $100 \mathrm{~mm}$ in height in the laboratory (see Figure 3). Because the soil beneath a wind turbine foundation is usually compacted to meet the desired bearing capacity, the compaction method was used to form soil specimens. Firstly, the soil was mixed at the optimum water content (i.e., 12.55\%). Then, it was added in a cylindrical mold and compacted by layers. The top surface of the soil was scraped to ensure uniformity of the specimen between every two layers. Three compaction degrees (i.e., 0.98, 0.95, and 0.92) were considered in order to simulate different compaction conditions of the soil. 
TABLe 1: Physical properties of the soil and bedrocks.

\begin{tabular}{lccccc}
\hline No. & Stratum & Thickness, $\mathrm{t}(\mathrm{m})$ & $\begin{array}{c}\text { Natural density, } \\
\rho\left(\mathrm{g} / \mathrm{cm}^{3}\right)\end{array}$ & $\begin{array}{c}\text { Optimum water content, } \\
\text { wopt }(\%)\end{array}$ & $\begin{array}{c}\text { Maximum dry density, } \rho \text { dmax } \\
\left(\mathrm{g} / \mathrm{cm}^{3}\right)\end{array}$ \\
\hline 1 & Residual soil & $5.1-8.2$ & 1.71 & 12.55 & 1.86 \\
2 & Strongly weathered sandstone & $4.2-6.8$ & 2.45 & - & - \\
3 & Moderately weathered sandstone & $>16.7$ & 2.55 & - & - \\
\hline
\end{tabular}

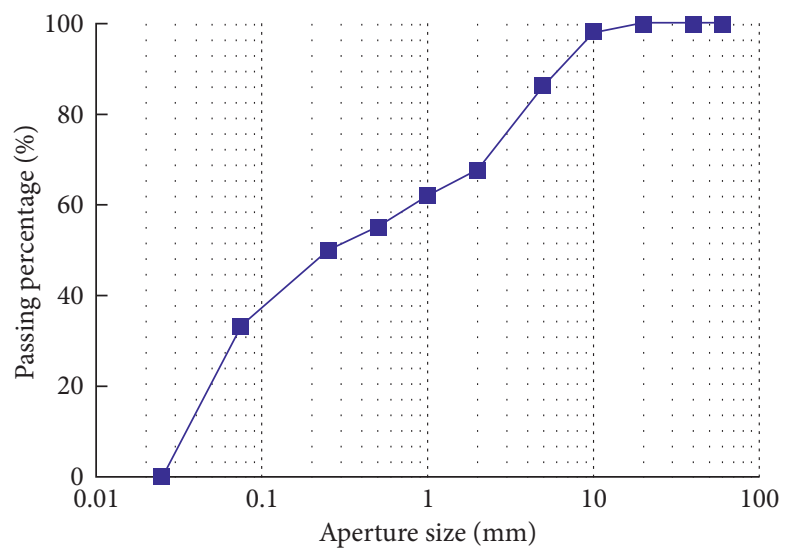

FIgURE 2: Grading curve of the residual soil.

TABLE 2: Grading parameters of the residual soil.

\begin{tabular}{lcccccccc}
\hline Parameter & Gravel and sand content (\%) & Silt content (\%) & Clay content (\%) & Cu & Cc & $D_{10}(\mathrm{~mm})$ & $D_{30}(\mathrm{~mm})$ & $D_{60}(\mathrm{~mm})$ \\
\hline Value & 32.3 & 34.3 & 33.4 & 27 & 0.1 & 0.03 & 0.06 & 0.81 \\
\hline
\end{tabular}

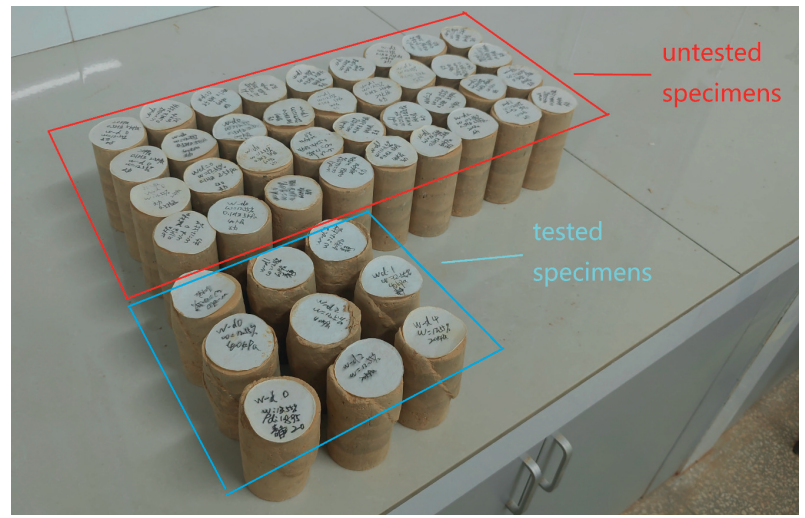

Figure 3: Cylindrical residual soil specimens.

2.3. Test Methods. Dynamic triaxial tests were performed to determine the shear strength of residual soils under cyclic drying-wetting and vibrating conditions. The instrument used in the tests was the GDS cyclic triaxial testing system (Figure 4). The tests could be divided into the cyclic dryingwetting phase, consolidation phase, and triaxial shearing phase when examining the influence of drying-wetting cycles on the shear strength. When the effect of vibrations was taken into account, a cyclic loading phase was introduced between the consolidation phase and triaxial shearing phase. The test schemes are shown in Table 3.

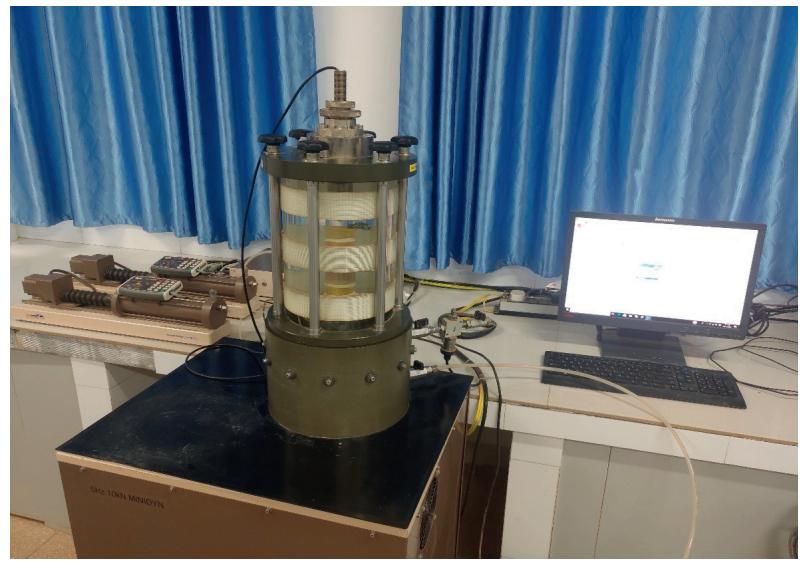

FIgURE 4: GDS cyclic triaxial testing system.

Preliminary tests were carried out to determine the drying and wetting time to achieve the target water content. The drying process was realized by drying the specimen in an oven at $104^{\circ} \mathrm{C}$ for $10 \mathrm{~h}$, after which the water content was reduced down to $7 \%$. The wetting process was achieved by soaking the specimen in water for $24 \mathrm{~h}$ after evacuation. The devices used in the wetting process are shown in Figure 5. The wetting process could cause the specimen to have a water content of $18 \%$ and a degree of saturation of about $90 \%$. Every drying-wetting cycle consisted of a drying 
TABLe 3: Test schemes.

\begin{tabular}{|c|c|c|c|c|}
\hline Factor & $\begin{array}{c}\text { Compaction } \\
\text { degree, } K\end{array}$ & $\begin{array}{l}\text { Number of drying-wetting } \\
\text { cycle, } n\end{array}$ & $\begin{array}{c}\text { Confining pressure, } \sigma_{3} \\
(\mathrm{kPa})\end{array}$ & $\begin{array}{l}\text { Amplitude of cyclic load, } \\
\Delta \sigma_{1}(\mathrm{kPa})\end{array}$ \\
\hline \multirow{15}{*}{ Drying-wetting cycle } & \multirow{5}{*}{0.98} & 0 & $20,40,60$ & \multirow[t]{5}{*}{$\mathrm{C}_{\mathrm{C}}$} \\
\hline & & 1 & $20,40,60$ & \\
\hline & & 2 & $20,40,60$ & \\
\hline & & 3 & $20,40,60$ & \\
\hline & & 4 & $20,40,60$ & \\
\hline & \multirow{5}{*}{0.95} & 0 & $20,40,60$ & \multirow{5}{*}{0} \\
\hline & & 1 & $20,40,60$ & \\
\hline & & 2 & $20,40,60$ & \\
\hline & & 3 & $20,40,60$ & \\
\hline & & 4 & $20,40,60$ & \\
\hline & \multirow{5}{*}{0.92} & 0 & $20,40,60$ & \multirow{5}{*}{0} \\
\hline & & 1 & $20,40,60$ & \\
\hline & & 2 & $20,40,60$ & \\
\hline & & 3 & $20,40,60$ & \\
\hline & & 4 & $20,40,60$ & \\
\hline \multirow{3}{*}{$\begin{array}{l}\text { Drying-wetting cycle and } \\
\text { vibration }\end{array}$} & \multirow{3}{*}{0.98} & 0 & $20,40,60$ & \multirow{3}{*}{$\begin{array}{c} \pm 5.0 \mathrm{kPa}(1000,5000, \text { and } 10000 \\
\text { vibrations })\end{array}$} \\
\hline & & 2 & $20,40,60$ & \\
\hline & & 4 & $20,40,60$ & \\
\hline
\end{tabular}

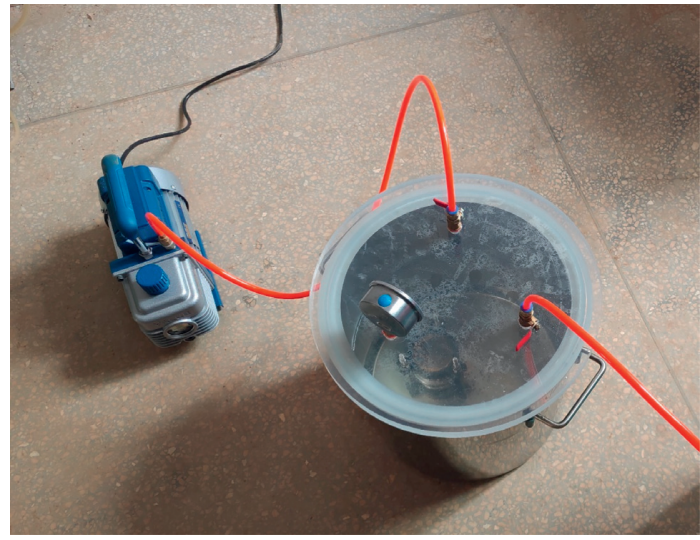

Figure 5: Devices used in the wetting process.

process and a wetting process, and the variation of water content was about $\pm 5.5 \%$ relative to the optimum water content (12.55\%). Different numbers of drying-wetting cycles (i.e., $0,1,2,3$, and 4) were imposed on the specimens, and a $2 \mathrm{~h}$ pause was considered between every two cycles.

Three levels of confining pressure (i.e., 20, 40, and $60 \mathrm{kPa}$ ) were employed in triaxial tests. The consolidation phase lasted $24 \mathrm{~h}$ at an isotropic confining pressure state. Three parallel tests were conducted for each test scheme. Triaxial shearing was performed under drained conditions at an axial strain rate of $0.003 \%$ ( $\mathrm{min}$ ). This loading rate was reduced if excess pore water pressure occurred. The shearing continues until the axial strain reached $10 \%$. The axial strain and axial stress were monitored.

According to the field monitoring work reported by Gao et al. [6], the contact pressure between the wind turbine foundation and the subsoil can be broken down into a longperiodic static component and a short-periodic dynamic component. The latter can be simplified to be a low-amplitude sinusoidal pressure. In this study, a cyclic axial pressure with an amplitude of $\pm 5 \mathrm{kPa}$ and a frequency of $0.5 \mathrm{~Hz}$ was used to analyze the effect of vibration on soil strengths. Figure 6 presents the diagram of the axial loading applied in a triaxial test with vibration.

\section{Results and Discussion}

3.1. Stress-Strain Relationships. Figure 7 illustrates the stress-strain curves of soil specimens with different compaction degrees affected by drying-wetting cycles. It shows that the influence of drying-wetting cycles on the mechanical behavior of residual soil varies at different compaction degrees. When the compaction degree is 0.98, the stressstrain curves of all specimens are characterized by strainsoftening behavior (Figure 7(a)). In this case, the maximum deviatoric stress generally occurs at an axial strain of $3 \%-4 \%$. The specimens still show strain-softening behavior at a compaction degree of 0.95 , but the curve peaks tend to be less obvious (Figure 6). When the compaction degree is reduced to 0.92 , the specimens after zero, one, and two drying-wetting cycles exhibit strain-softening behavior, but those after three and four drying-wetting cycles show strainhardening behavior (Figure 6). It is also noted that the failure mode of the specimens is affected by the confining pressure. As shown in Figure 8, the failure mode changes from a single failure surface to two intersected failure surfaces with increasing confining pressure.

The soil specimens were prepared at high compaction degrees $(K=0.92-0.98)$ while they were consolidated at relatively small confining pressures $\left(\sigma_{3}=20-60 \mathrm{kPa}\right)$, so they possess similar characteristics to overconsolidated soils. This is why all specimens before the cyclic drying-wetting process show strain-softening behavior. Since the residual soil contains a large number of clay minerals such as montmorillonite and illite, it shows shrinkage and expansion during the cyclic drying-wetting process. The repeated shrinkage and expansion will lead to crack development and destroy the internal 


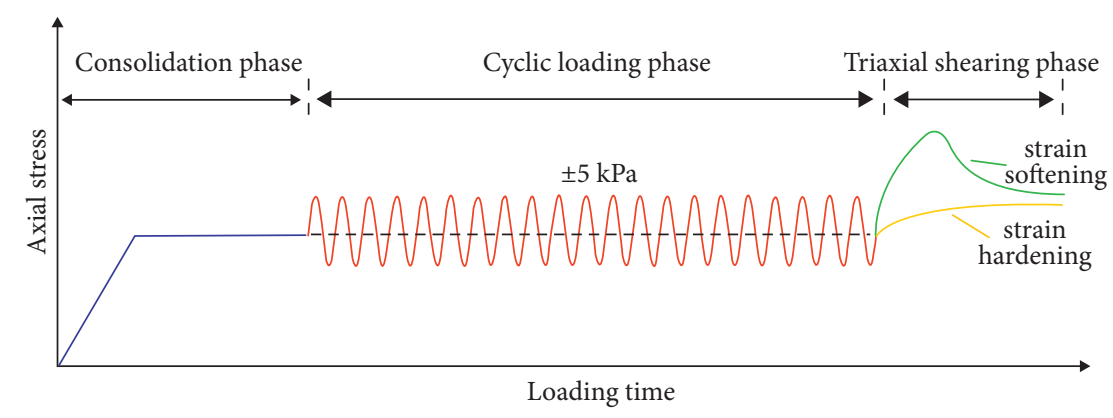

Figure 6: Loading diagram for triaxial tests on residual soil specimens with vibration.

structure of residual soils. As a result, the shear strength reduces during the cyclic drying-wetting process. The phenomenon is more prominent for the specimen of a smaller compaction degree. This is because the larger the compaction degree is, the smaller the initial porosity is and the stronger the contact between particles becomes, which can better restrain the development of cracks and protect the original structure of soil. Hence, the specimens with $K=0.95$ and 0.98 always show strain-softening behavior although they experienced several drying-wetting cycles. By contrast, when the compaction degree is 0.92 , the stress-strain curve is transferred from the strain-softening type to the strain-hardening type. The above phenomenon indicates that drying-wetting cycles will damage the internal structure of residual soils, and an increase in compaction degree can effectively inhibit the damaging effect.

Figure 9 depicts the influences of the drying-wetting cycle $(n)$ and compaction degree $(K)$ on the maximum deviatoric stress, $(\sigma 1-\sigma 3) \max$, of residual soil at different confining pressures. It is observed that drying-wetting cycles have an obvious deteriorative effect on the maximum deviatoric stress of compacted residual soil. At a given compaction degree, the maximum deviatoric stress reduces as the number of drying-wetting cycles increases, but the reduction becomes less obvious after three drying-wetting cycles. Meanwhile, the increase of compaction degree can restrain the deteriorative effect. For example, at a confining pressure of $40 \mathrm{kPa}$, the maximum deviatoric stress of the specimen with $K=0.92$ reduces by $59.3 \%$ after four drying-wetting cycles; by contrast, when $K=0.98$, the reduction of maximum deviatoric stress is only $34.1 \%$. This suggests that the compaction degree of the soil should be strictly controlled in the construction phase; otherwise, the bearing capacity will degrade and cause instability of the wind turbine foundation due to the effect of cyclic drying-wetting environment.

3.2. Shear Strength Parameters. Figure 10 plots the change of shear strength parameters (i.e., cohesion $c$ and angle of internal friction $\varphi$ ) as the drying-wetting cycle $n$ and compaction degree $K$ increase. The shear strength parameters were acquired from Mohr's circle.

As shown in Figure 10(a), when $K$ is constant, the $c$ value first shows an obvious decrease and then tends to be stable as the $n$ value increases from 0 to 4 . This indicates that the deteriorative effect of drying-wetting cycles on the cohesion is mainly manifested in the first three drying-wetting cycles. When $n$ is constant, $c$ decreases linearly with the reduction in $K$. Thus, $c$ can be expressed as a function of $n$ and $K$ :

$$
\begin{aligned}
c & =-137.42[1+0.08 \ln (n+1)-1.37 K], \\
R^{2} & =0.9023 .
\end{aligned}
$$

Figure 10(b) shows that the angle of internal friction is almost not affected by drying-wetting cycles, while it linearly increases with the increase in compaction degree. The relationship between the angle of internal friction and compaction degree can be fitted by the following equation:

$$
\begin{aligned}
\varphi & =123.2 K-86.8, \\
R^{2} & =0.9257 .
\end{aligned}
$$

Figure 11 presents the photos of specimens with different compaction degrees (i.e., 0.92, 0.95, and 0.98) after shear failures. It is observed that the angle $(\alpha \mathrm{f})$ between the failure surface and the major principle stress direction reduces as the compaction degree increases. Theoretically, this angle can be expressed by the angle of internal friction:

$$
\alpha_{f}=45^{\circ}-\frac{\varphi}{2} \text {. }
$$

Equation (3) shows that the larger the angle of internal friction, the smaller the angle $\alpha \mathrm{f}$. This confirms the positive correlation between the angle of internal friction and the compaction degree in Figure 10(b).

The cohesion of geomaterials usually comes from the cementing force, electrostatic force, van der Waals force, etc. [18], among which the cementing force is the most important component. The cyclic drying-wetting process continuously causes the development of microcracks in soil. This will reduce the cementing force and finally lead to a decrease in cohesion. As for the angle of internal friction, on the one hand, the existence of microcracks will reduce the angle of internal friction; on the other the hand, cyclic drying-wetting process will cause fine particles to form aggregate, leading to the increase of interlocking force and friction. It is found that the angle of internal friction is almost not affected by drying-wetting cycles. This is probably due to the counterbalance between the above two effects. 

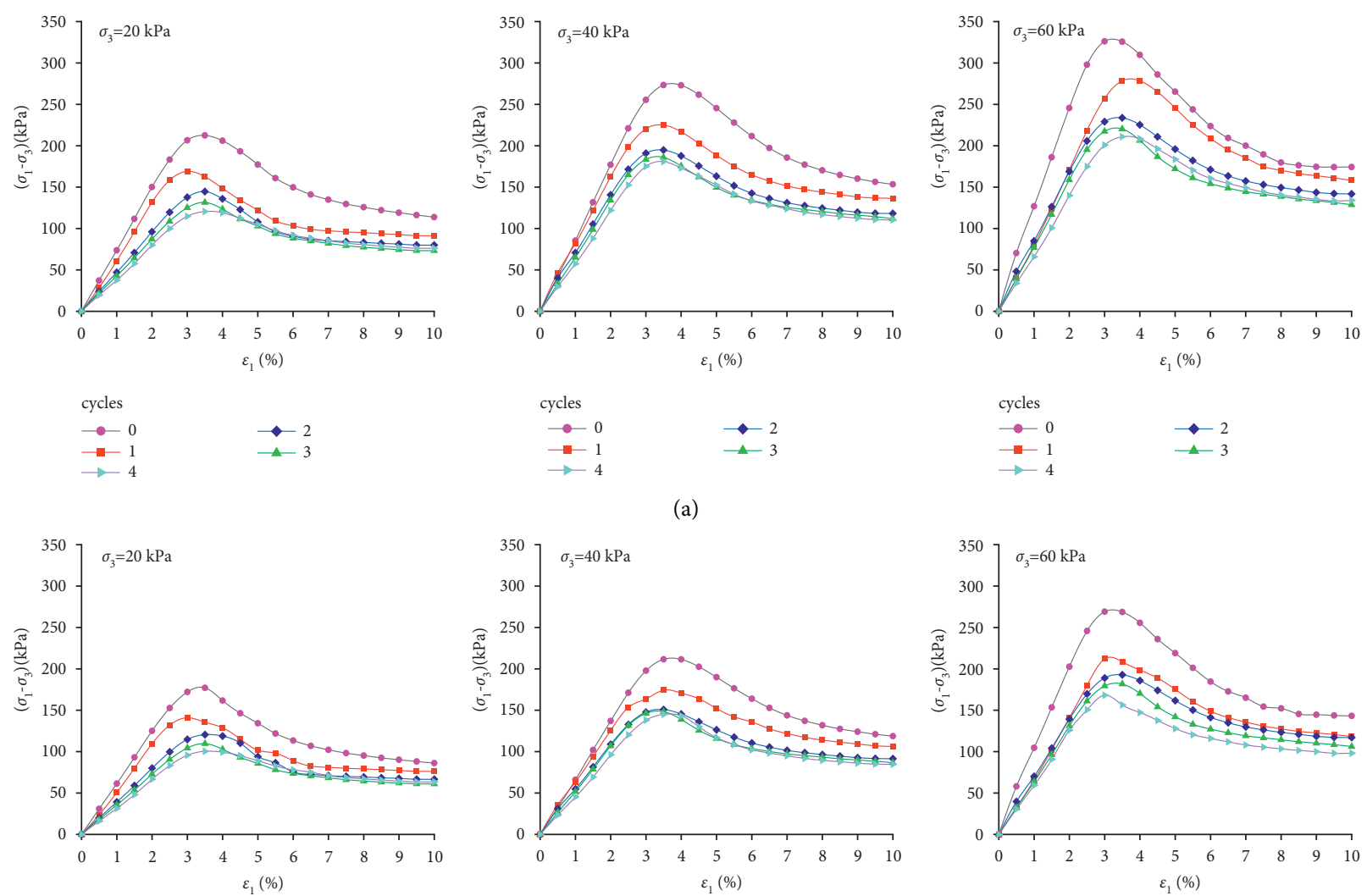
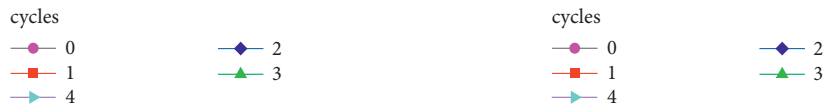

(b)

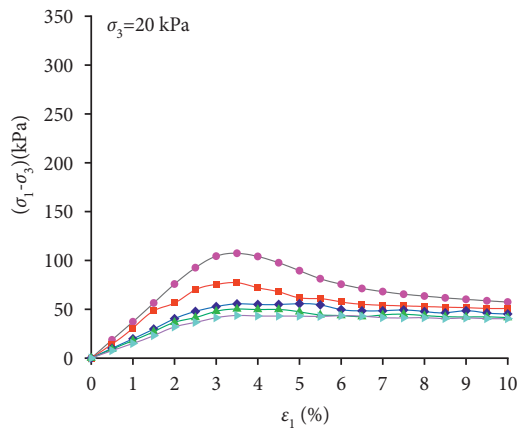

cycles

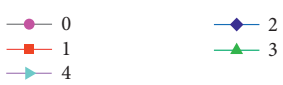

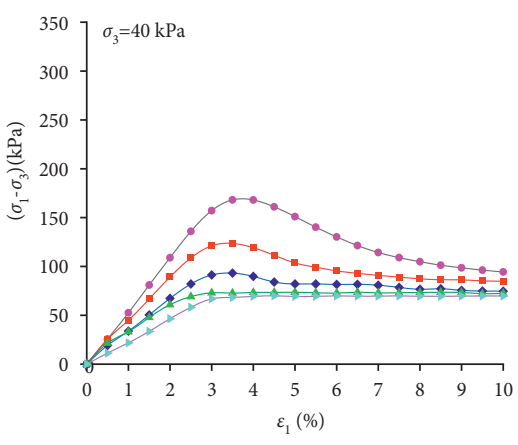

cycles

$\because 0$

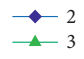

(c)
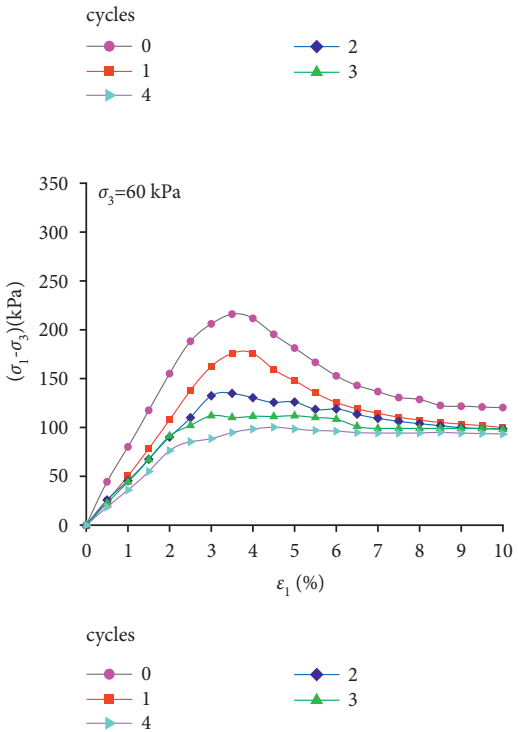

FIgURE 7: Stress-strain curves of compacted residual soil: (a) $K=98 \%$; (b) $K=95 \%$; (c) $K=92 \%$.

\section{Effect of Vibrations on Shear Strengths}

The influence of continuous vibrations on the mechanical behavior of residual soils is analyzed. Figure 12 shows the stress-strain curves of the specimens under a confining pressure of $20 \mathrm{kPa}$ after cyclic drying-wetting process and continuous vibrations.

It is observed that continuous vibrations also have obvious deteriorative effects on the strength of specimens free of cyclic drying-wetting process (Figure 12(a)). The maximum deviatoric stress decreases by $23.2 \%$ after 1000 vibrations, but the decreasing rate slows down as the number of vibrations increases. When the vibrating number rises up to 10000 , the stress-strain curve and maximum deviatoric stress begin to stabilize. In addition, as shown in Figures 12(b) and 12(c), the specimen that has undergone many drying-wetting cycles is not sensitive to continuous vibrations. 


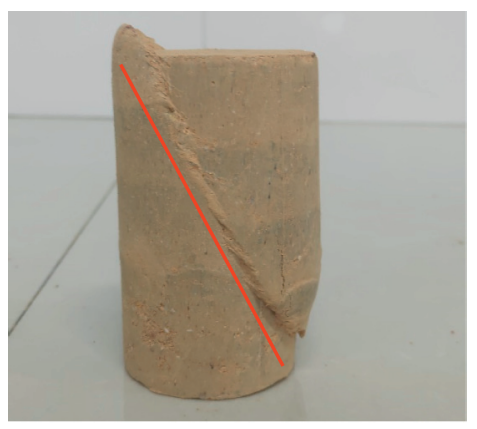

(a)

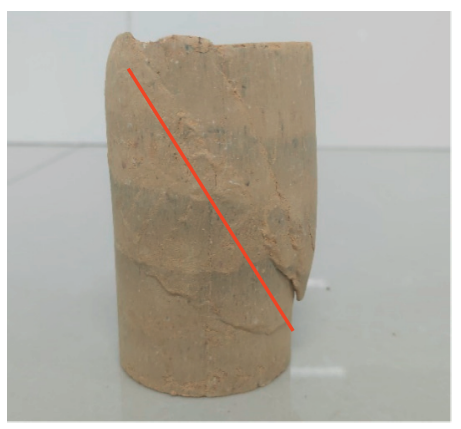

(b)

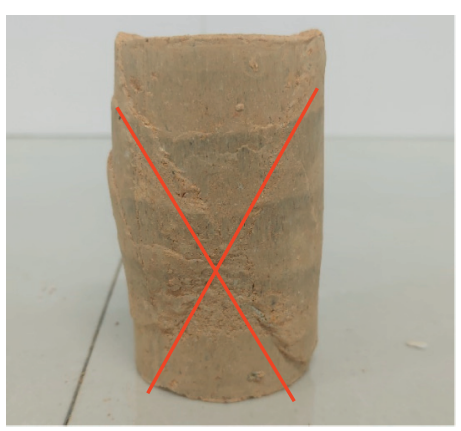

(c)

FIgURE 8: Failure mode of soil specimens with $K=0.98$ and $n=0$ : (a) $\sigma_{3}=20 \mathrm{kPa}$; (b) $\sigma_{3}=40 \mathrm{kPa}$; (c) $\sigma_{3}=60 \mathrm{kPa}$.

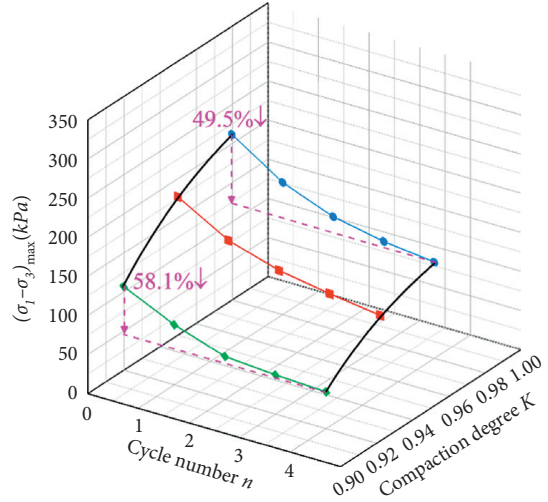

(a)

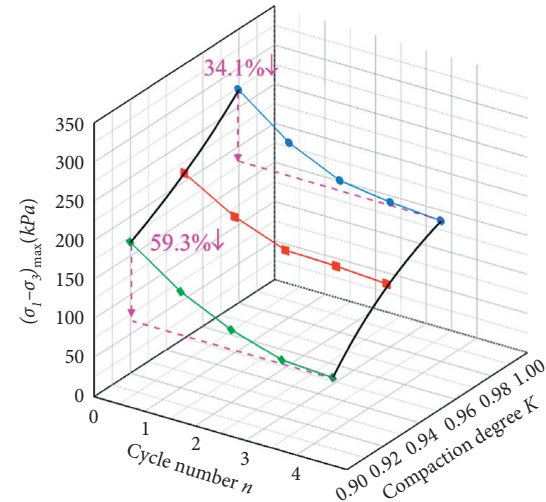

(b)

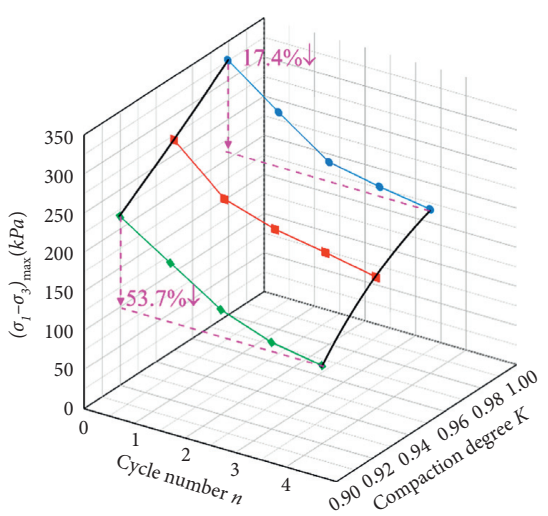

(c)

Figure 9: Strength variations of compacted residual soil: (a) $\sigma_{3}=20 \mathrm{kPa}$; (b) $\sigma_{3}=40 \mathrm{kPa}$; (c) $\sigma_{3}=60 \mathrm{kPa}$.

Table 4 shows the shear strength parameters of specimens after 10000 vibrations. One can note that both the cohesion and angle of internal friction exhibit dynamic attenuation effects after continuous vibrations. Thus, the dynamic attenuation coefficients of cohesion and angle of internal friction are $0.5-0.7$ and $0.8-0.9$, respectively, considering that a lower compaction degree will lead to a stronger dynamic attenuation effect. Obviously, a larger coefficient should be taken when the compaction degree is high, and vice versa.

In general strength formulas of soils, such as the Mohr-Coulomb strength equation, the cohesion and angle of internal friction are regarded as constant. This is not necessarily applicable to soils suffering from cyclic dryingwetting process and continuous vibrations. Therefore, the Mohr-Coulomb strength equation is modified to consider the influences of drying-wetting cycle number, compaction degree, and dynamic attenuation coefficients:

$$
\begin{aligned}
& \tau=c+\sigma \tan \phi, \\
& c=137.42 \xi[1.37 K-0.08 \ln (n+1)-1], \\
& \phi=(123.2 K-86.8) \zeta,
\end{aligned}
$$

where $\tau$ is the shear strength, $\sigma$ is the normal stress on the shear surface, $\xi$ is the dynamic attenuation coefficient of the cohesion, and $\zeta$ is the dynamic attenuation coefficient of the angle of internal friction.

Equation (4) not only reflects the evolution of shear strengths of compacted residual soil with drying-wetting cycles and compaction degrees, but also considers the continuous vibrating effect due to the wind-induced dynamic load transferred from the superstructure of wind turbine. Therefore, this equation can be used to calculate the stability of wind turbine foundation relying on residual soils.

\section{Discussion on Bearing Capacity}

A wind turbine is mainly composed of a wind rotor, a nacelle, a tower, and a foundation. Due to the eccentric center of the wind rotor and nacelle as well as the presence of horizontal wind loads, the subsoil is usually eccentrically compressed with an eccentricity $e$ less than $0.033 \mathrm{~b}(\mathrm{~b}$ is the foundation width, and it is set to be $6 \mathrm{~m}$ when $b>6 \mathrm{~m}$ ). Thus, the bearing capacity of the soil can be estimated by [22]

$$
f_{a}=M_{b} \gamma b+M_{d} \gamma_{m} d+M_{c} c,
$$

where $f_{a}$ is the characteristic value of bearing capacity; $M_{b}$, $M_{d}, M_{c}$ are bearing capacity parameters given in [22]; $\gamma$ is the 


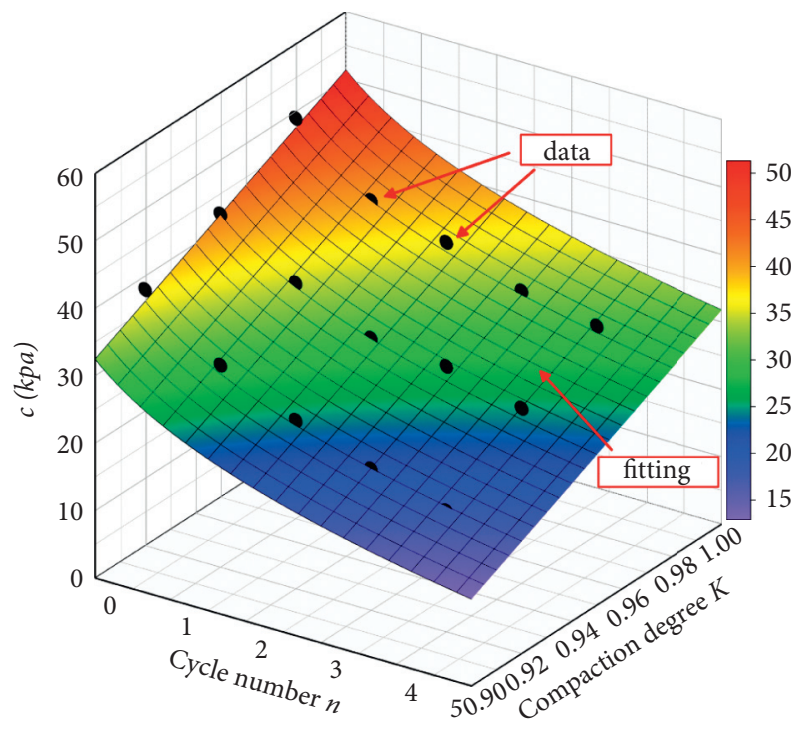

(a)

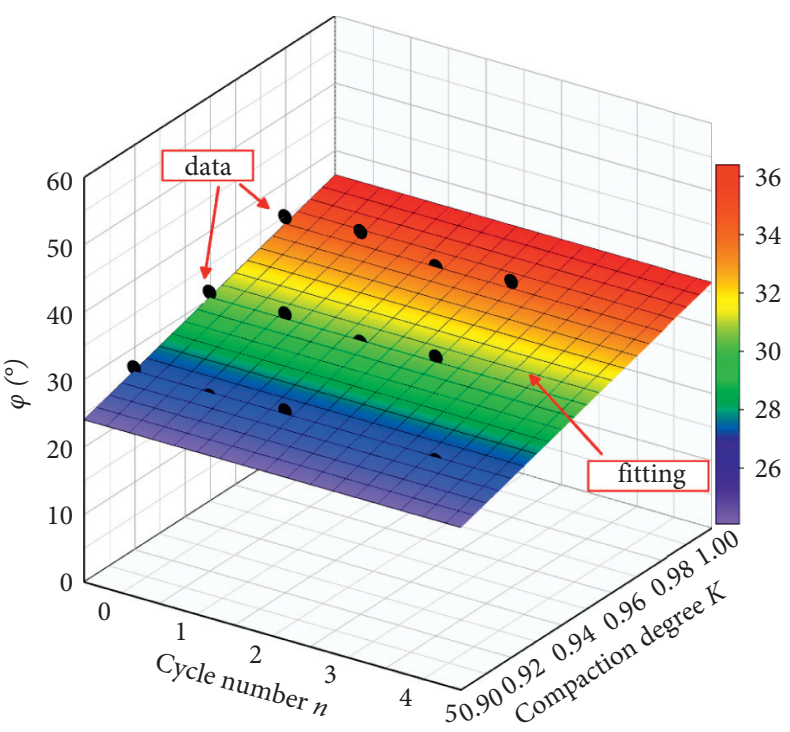

(b)

Figure 10: Influences of drying-wetting cycles and compaction degree on shear strength parameters: (a) cohesion; (b) angle of internal friction $\varphi$.

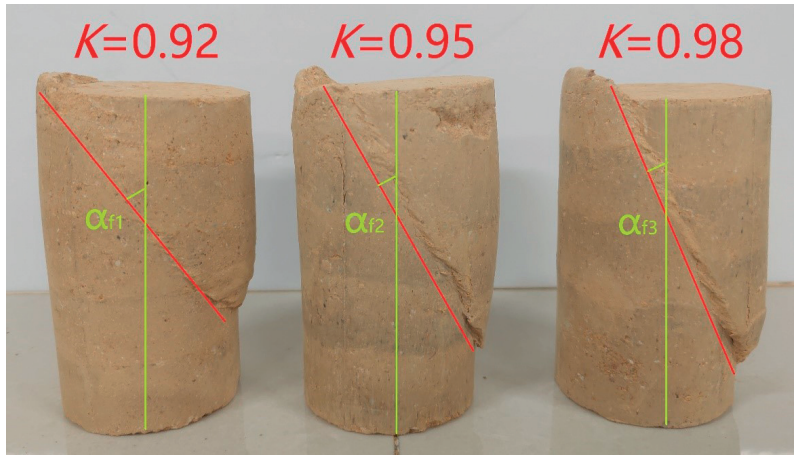

FIGURE 11: Angle between the failure surface and major principal stress direction $\left(n=0, \sigma_{3}=20 \mathrm{kPa}\right)$.

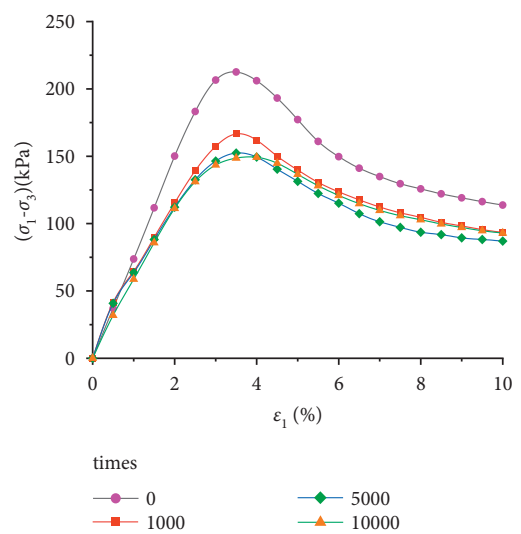

(a)

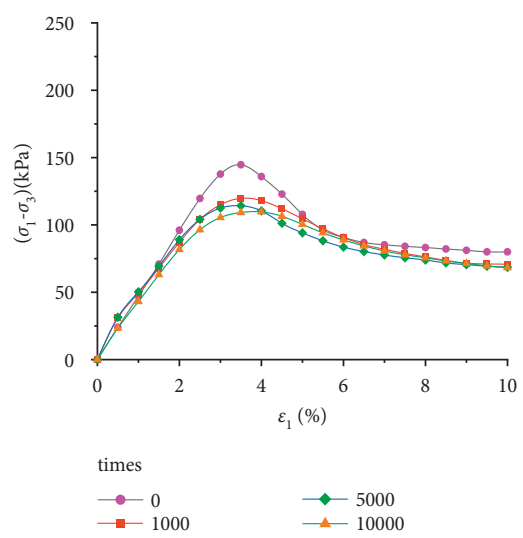

(b)

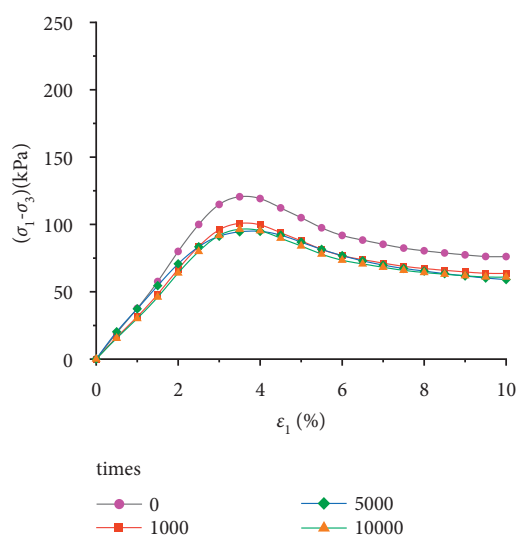

(c)

FiguRE 12: Stress-strain curves of the specimens under $\sigma_{3}=20 \mathrm{kPa}$ affected by vibrations: (a) $n=0$; (b) $n=2$; (c) $n=4$. 
TABLE 4: Variation of shear strength parameters after vibrations.

\begin{tabular}{|c|c|c|c|c|c|}
\hline \multirow[t]{2}{*}{ Compaction degree } & \multirow[t]{2}{*}{ Drying-wetting cycle, $n$} & \multicolumn{2}{|c|}{ Cohesion, $c(\mathrm{kPa})$} & \multicolumn{2}{|c|}{$\begin{array}{c}\text { Angle of internal friction, } \\
\varphi\left({ }^{\circ}\right)\end{array}$} \\
\hline & & Value & Reduction & Value & Reduction \\
\hline \multirow{3}{*}{0.98} & 0 & 29.6 & $-39.5 \%$ & 29.3 & $-16.3 \%$ \\
\hline & 2 & 24.2 & $-34.7 \%$ & 29.1 & $-14.2 \%$ \\
\hline & 4 & 21.2 & $-31.7 \%$ & 28.3 & $-14.3 \%$ \\
\hline
\end{tabular}

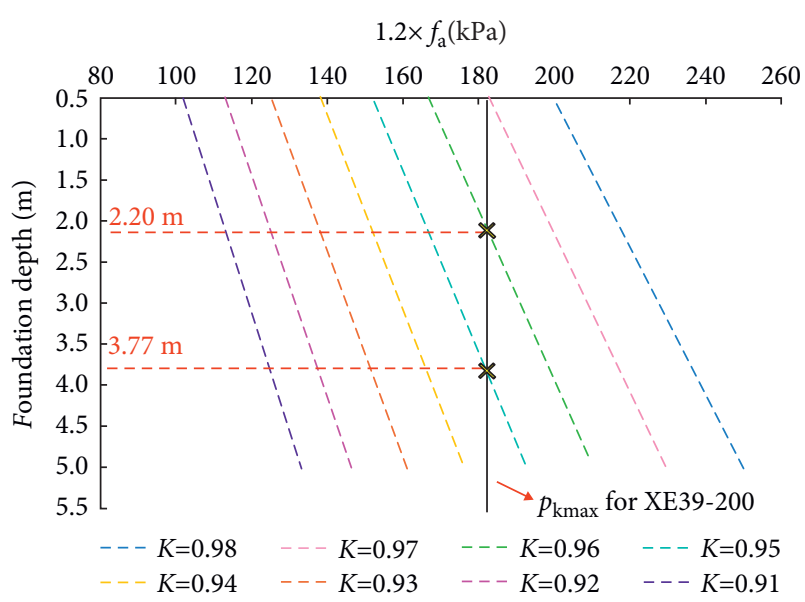

FIgURE 13: Relationship between the bearing capacity and embedded depth of foundation.

average unit weight of soil below the foundation; $\gamma_{m}$ is the average unit weight of soil above the foundation bottom; $d$ is the foundation depth; and $c$ is the cohesion of the soil below the foundation bottom.

According to the Chinese specification [22], the maximum contact pressure should not be larger than $1.2 f_{a}$ for compression with small eccentricity. With the consideration of the long-term variation of bearing capacity, $n, \xi$, and $\zeta$ are assumed to be $4,0.6$, and 0.85 , respectively. Therefore, the cohesion and angle of internal friction of residual soil with different compaction degrees can be determined from (5) and (6). Finally, the bearing capacity of the soil is estimated based on (7). It is worth pointing out that almost all the foundation width of turbine surpasses $6 \mathrm{~m}$, so $b$ is supposed to be $6 \mathrm{~m}$ in the calculation.

Figure 13 presents the bearing capacity as a function of the embedded depth of the foundation. The maximum contact pressure $\left(p_{\mathrm{kmax}}=183.0 \mathrm{kPa}\right)$ below the shallow foundation of a typical $2 \mathrm{MW}$ horizontal-axis wind turbine reported by [23] is also plotted in the figure. It is noted that if a compaction degree of 0.96 is used to treat the subsoil, the embedded depth of the foundation should be larger than $2.2 \mathrm{~m}$; if a compaction degree of 0.95 is used to treat the subsoil, the embedded depth of the foundation should be larger than $3.77 \mathrm{~m}$; otherwise, the subsoil will not be able to support the foundation steadily. The above results can provide guidance for the design of wind turbine foundations on residual soils considering both the cyclic drying-wetting environment and the continuous vibration of the wind turbine.

\section{Conclusions}

The following conclusions can be drawn:

The shear strength of compacted residual soil gradually reduces as the number of drying-wetting cycles increases, but it tends to be stable after three drying-wetting cycles. The drying-wetting cycle has a certain deteriorative effect on the internal structure of residual soil, and an increase in compaction degree can effectively restrain the deteriorative effect.

With the increase in drying-wetting cycle number, the cohesion decreases rapidly and then tends to be stable. The deteriorative effect of drying-wetting cycles on the cohesion is mainly manifested in the first three drying-wetting cycles. The angle of internal friction is not significantly affected by drying-wetting cycles, but it decreases linearly with the decrease in compaction degree.

After continuous vibrations, the strength of compacted residual soil decreases. When the vibrating number increases up to 10000 , the stress-strain curve and strength begin to stabilize. However, the specimens that have been subjected to many drying-wetting cycles are not sensitive to continuous vibrations.

The dynamic attenuation coefficients of cohesion and angle of internal friction are recommended to be $0.5-0.7$ and 0.8-0.9, respectively. A modified Mohr-Coulomb strength equation that considers the deteriorative effects of drying-wetting cycles and continuous vibrations is established. This equation can be used to predict the shear strength of compacted residual soils underlying wind turbines.

Based on the modified Mohr-Coulomb strength equation, the embedded depth of wind turbine foundations at different compaction degrees is estimated. The finding provides a reference for the design of wind turbine foundations in mountainous areas with the consideration of cyclic drying-wetting environment and continuous vibrations.

\section{Data Availability}

Because the data in the paper are still part of a project of the National Natural Science Foundation of China, they need to be used in the follow-up study of the project. Therefore, all the figures and tables data used to support the findings of this study were supplied by the corresponding author under license and so cannot be made freely available. Requests for access to these data should be made to Deng Zong-Wei, Hunan City University, No. 518, Yingbin East 
Road, 413000, Yiyang, Hunan, China (e-mail: dengzongwei@hncu.edu.cn).

\section{Conflicts of Interest}

The authors declare that they have no conflicts of interest.

\section{Acknowledgments}

This work was supported by the Natural Science Foundation of Hunan Province, China (2020JJ4156 and 2021JJ50142); the National Natural Science Foundation of China (51674041 and 51474103); and the Changsha Municipal Natural Science Foundation (kq2014110).

\section{References}

[1] Z.-W. Deng, Q.-F. Gao, H. Dong, and L.-X. Li, "Dynamic responses of the shallow foundation of an onshore wind turbine," International Journal of Physical Modelling in Geotechnics, vol. 19, no. 5, pp. 247-260, 2019.

[2] X.-c. Fan and W.-q. Wang, "Spatial patterns and influencing factors of China's wind turbine manufacturing industry: a review," Renewable and Sustainable Energy Reviews, vol. 54, pp. 482-496, 2016.

[3] L. Li, X. Ren, Y. Yang, P. Zhang, and X. Chen, "Analysis and recommendations for onshore wind power policies in China," Renewable and Sustainable Energy Reviews, vol. 82, pp. 156167, 2018.

[4] L. Zeng, F. Li, Q. F. Gao, X. Yao, and G. Wang, "Insight into the fracturing of silty mudstone in cyclic hydrothermal environments based on computed tomography," Transportation Geotechnics, vol. 26, Article ID 100432, 2021.

[5] P. Liu, R. P. Chen, K. Wu, and X. Kang, "Effects of dryingwetting cycles on the mechanical behavior of reconstituted granite-residual soils," Journal of Materials in Civil Engineering, vol. 32, no. 8, 2020.

[6] Q.-F. Gao, H. Dong, Z.-W. Deng, and Y.-Y. Ma, "Wind-induced dynamic amplification effects on the shallow foundation of a horizontal-axis wind turbine," Computers and Geotechnics, vol. 88, pp. 9-17, 2017.

[7] M. J. Vahdatirad, D. V. Griffiths, L. V. Andersen, J. D. Sørensen, and G. A. Fenton, "Reliability analysis of a gravity-based foundation for wind turbines: a code-based design assessment," Géotechnique, vol. 64, no. 8, pp. 635-645, 2014.

[8] M. M. Liu, M. Yang, and H. J. Wang, "Study on subgrade reaction and punching of circular spread foundation for onshore wind turbines," Acta Energiae Solaris Sinica, vol. 36, no. 5, pp. 1130-1135, 2015, (In Chinese).

[9] C. Pasten, A. M. Asce, H. Shin, and C. Santamarina, "Longterm foundation response to repetitive loading," Journal of Geotechnical and Geoenvironmental Engineering, vol. 140, no. 36, pp. 1-11, 2014.

[10] A. Madaschi, A. Gajo, M. Molinari, and D. Zonta, "Characterization of the dynamic behavior of shallow foundations with full-Scale dynamic tests," Journal of Geotechnical and Geoenvironmental Engineering, vol. 142, no. 38, pp. 21-30, 2016.

[11] A. R. Russell and N. Khalili, "A unified bounding surface plasticity model for unsaturated soils," International Journal for Numerical and Analytical Methods in Geomechanics, vol. 30, no. 3, pp. 181-212, 2006.
[12] W. G. Li and Q. Yang, "Hydromechanical constitutive model for unsaturated soils with different overconsolidation ratios," International Journal of Geomechanics, vol. 18, no. 2, Article ID 04017142, 2018.

[13] B. Xu, Z. Z. Yin, and S. L. Liu, "Experimental study of factors influencing expansive soil strength," Rock and Soil Mechanics, vol. 32, no. 1, pp. 44-50, 2011, (in Chinese).

[14] M. H. T. Rayhani, E. K. Yanful, and A. Fakher, "A.Physical modeling of desiccation cracking in plastic soils," Engineering Geology, vol. 97, no. 1-2, pp. 25-31, 2008.

[15] M. H. Rayhani, E. K. Yanful, and A. Fakher, "Desiccationinduced cracking and its effect on the hydraulic conductivity of clayey soils from Iran," Canadian Geotechnical Journal, vol. 44, no. 3, pp. 276-283, 2007.

[16] J. J. Zhang, B. W. Gong, and B. Hu, "Study of evolution law of fissures of expansive clay under wetting and drying cycles," Rock and Soil Mechanics, vol. 32, no. 9, pp. 2729-2734, 2011, (in Chinese).

[17] C. W. W. Ng, J. Xu, and S. Y. Yung, "Effects of wetting-drying and stress ratio on anisotropic stiffness of an unsaturated soil at very small strains," Canadian Geotechnical Journal, vol. 46, no. 9, pp. 1062-1076, 2009.

[18] M. Monghassem, M. Ajdari, S. M. Binesh, and F. Vahedifard, "Effects of suction and drying-wetting cycles on shearing response of adobe," Journal of Materials in Civil Engineering, vol. 133, no. 7, pp. 1-15, 2021.

[19] A. Pasculli, N. Sciarra, L. Esposito, and A. W. Esposito, "Effects of wetting and drying cycles on mechanical properties of pyroclastic soils," Catena, vol. 156, pp. 113-123, 2017.

[20] H. M. D. Sayem, "Effect of drying-wetting cycles on saturated shear strength of undisturbed residual soils," American Journal of Civil Engineering, vol. 4, no. 4, pp. 159-166, 2016.

[21] Ministry of Housing and Urban-Rural Development, $G B$ Chinese Specification for the Design of Building Foundations, China Building Industry Press, Beijing, 2011, in Chinese.

[22] Ministry of Housing and Urban-Rural Development, $P R C, G B$ 50007-2011 Chinese Specification for the Design of Building Foundations, China Building Industry Press, Beijing, China, 2011, in Chinese.

[23] Z. W. Deng, W. C. Peng, and Q. F. Gao, "Base pressure monitoring and flatness analysis for wind turbine spread subgrade," Rock and Soil Mechanics, vol. 36, no. 9, pp. 2659-2664, 2015, in Chinese. 